Sharif University of Technology
Scientia Iranica
SCIENTIA

Research Note

\title{
Enhancing power system transient stability using optimal unified power flow controller based on Lyapunov control strategy
}

\author{
P. Avaz Pour ${ }^{a, *}$ A. Lashkar Ara ${ }^{a}$ and S.A. Nabavi Niaki ${ }^{b}$ \\ a. Department of Electrical Engineering, Dezful Branch, Islamic Azad University, Dezful, P.O. Box 313, Iran. \\ b. Department of Electrical and Computer Engineering, University of Toronto, Toronto, ON M5 S 3G4, Canada.
}

Received 10 August 2015; received in revised form 13 May 2016; accepted 24 December 2016

KEYWORDS
OUPFC;
UPFC;
FACTS;
CLF;
Lyapunov.

KEYWORDS

FACTS;

Lyapunov.

\begin{abstract}
This paper presents a new control strategy for an Optimal Unified Power Flow Controller (OUPFC) through a Lyapunov energy function in terms of local parameters to improve the transient stability of a power system. The OUPFC is a hybrid configuration of Flexible AC Transmission System (FACTS) devices, i.e. an arrangement of small-sized Unified Power Flow Controller (UPFC) and a full-scale Phase Shifting Transformer (PST). In this study, a new term of OUPFC's energy function and its injection model in a simplified structure preserving model is developed and implemented in a two-machine power system using MATLAB/Simpower. The ability of the OUPFC controller to enhance the transient stability is compared to that of UPFC. The results show that using the proposed control strategy for OUPFC leads to more abatement of the first swing oscillations and enlargement of stability margin. It is concluded that compensation of UPFC's angle displacement may come true using OUPFC with appropriate angles in proper locations. So, compared to UPFC, OUPFC enjoys another degree of freedom.

(C) 2017 Sharif University of Technology. All rights reserved.
\end{abstract}

\section{Introduction}

Nowadays, power systems encounter a wide variety of disturbances such as short circuits on transmission lines or loss of large generators [1]. It has led to applying various technologies and techniques to mitigate the faults and their influence on the power grid and reduce the risk of blackouts [2]. In this regard, the Flexible AC Transmission System (FACTS) devices are commonly used in the existing power systems [3]. Unified Power Flow Controller (UPFC) is the most versatile and

*. Corresponding author. Tel.:: +986416260051; Fax: +986416260890

E-mail addresses: pantea_avazpour@yahoo.com (P. Avaz

Pour); Lashkarara@ieee.org (A. Lashkar Ara)

nabavi.niaki@utoronto.ca (S.A.NabaviNiaki) controllable parallel-series compensator [4,5] due to its capabilities such as improving transient stability [6] and the power flow control [7]. By installing UPFC in proper locations, supplementary control scheme may be added which aids the common controllers, such as Power System Stabilizers (PSSs) and Automatic Voltage Regulators (AVRs), to enhance the system operation. Due to the non-linear characteristics of these devices, the design of an effective controller is complicated. Common methods applied to transient stability control strategy are the equal area criterion [8], the numerical methods [9], and the direct methods (Lyapunov method) [10]. The effective performance of the direct methods to control Series Controllers (SCs) has been studied as transient stability assessment [11]. In addition, these methods are suitable for on-line dynamic security assessment due to simple mathematical op- 
erations, unlike numerical methods which numerically solve differential equations [12]. Also, while the equal area criterion [8] requires the pre-fault and post-fault, or stable-equilibrium points, direct methods may only need to solve the differential equation up to the point where the fault is cleared [10]. In Lyapunov method, the stability properties of equilibrium points of linear and nonlinear systems are characterized in terms of dynamic Lyapunov functions. The relation between these functions and Lyapunov functions has been studied to find a good controller [13]. Foregoing reasons lead to future studies on obtaining associated FACTS Lyapunov-based controller such as Controllable-Series Devices (CSD) [10], Static VAR Compensator (SVC) [14,15], UPFC [16,17], Thyristor Controlled-Series Capacitor (TCSC) $[18,19]$, etc.

Conventional FACTS controllers, such as Phase Shifting Transformers (PSTs), are also effective power flow controllers with their ability to control power flow in a power system, which have long been recognized [20]. An arrangement of a small-sized UPFC and a full-scale PST is called Optimal Unified Power Flow Controller (OUPFC) [21] which is a significant hybrid FACTS device in comparison with a standalone UPFC; it is a more cost-effective device. OUPFC's specific structure also provides almost the same compensation for the angle displacement as that of UPFC. The steady-state and dynamic models of UPFC are presented in [22]. The steady-state model of OUPFC [21] and its optimal location under normal and contingency operations are introduced in [23-25]. A generalized approach for determination of optimal location of OUPFC is also investigated in [26].

In this paper, the OUPFC is used to mitigate the transient stability. According to the characteristics of OUPFC, to the best of our knowledge, no research work has been reported on the OUPFC's impact on the transient stability. Therefore, the main contribution of this paper is to find an appropriate controller for an OUPFC to enhance the power system operation. Network topology's changes, due to disturbances, typically result in nonlinear system response. Therefore, an online control strategy that can respond to severe disturbances is required. Moreover, a Lyapunov-based control strategy for electromechanical power oscillations damping is implemented by using local input signals. The energy function of UPFC and OUPFC devices is derived and modeled in a two-machine power system, and is validated by simulation in the MATLAB/Simpower. Furthermore, the results obtained by OUPFC show that the OUPFC is outperformed by $\mathrm{UPFC}$ in the power system stability from the transient stability's point of view.

The remainder of the paper is organized as follows. Section 2 describes the principles and models of UPFC and OUPFC. Section 3 explains direct methods and control Lyapunov functions of the utilized FACTS. In Section 4, the case study and also simulation results are illustrated. Section 5 presents the conclusion.

\section{Principles and models}

The mathematical models of a power system, including network model, UPFC, and OUPFC, for formulating the stability problem are presented in the following subsections.

\subsection{Network model}

A simplified Structure Preserving Model (SPM) of a multi-machine power system is used for the synchronous generators and loads modeling, which is relatively close to real power system operation. Due to movement of operating condition of generators to a different state, when a fault occurs in the system, the dynamics of $i$ th generator for a system with $M$ generator buses and $N$ load buses without exciter and governor and without losses (Figure 1) are described by the following differential equations [24]:

$$
\begin{gathered}
\dot{\delta}_{i}=\omega_{i}, \\
M_{i} \dot{\omega}_{i}=P_{m i}-P_{G i}-D_{i} \omega_{i} \quad i=1, \ldots, M, \\
T_{d o i}^{\prime} \dot{E}_{q i}^{\prime}=\frac{x_{d i}-x_{d i}^{\prime}}{x_{d i}^{\prime}} V_{M+i} \cos \left(\delta_{i}-\theta_{M+i}\right) \\
\quad+E_{f d i}-\frac{x_{d i}}{x_{d i}^{\prime}} E_{q i}^{\prime} .
\end{gathered}
$$

Thus, assuming that $E_{f d i}, \bar{E}^{\prime}{ }_{i}=E_{i}^{\prime}<\delta_{i}(i=1, \ldots, M)$ and $\bar{V}_{i}=V_{i}<\theta_{i}(i=M+1, \ldots, M+N)$ are constant, active and reactive powers are [25]:

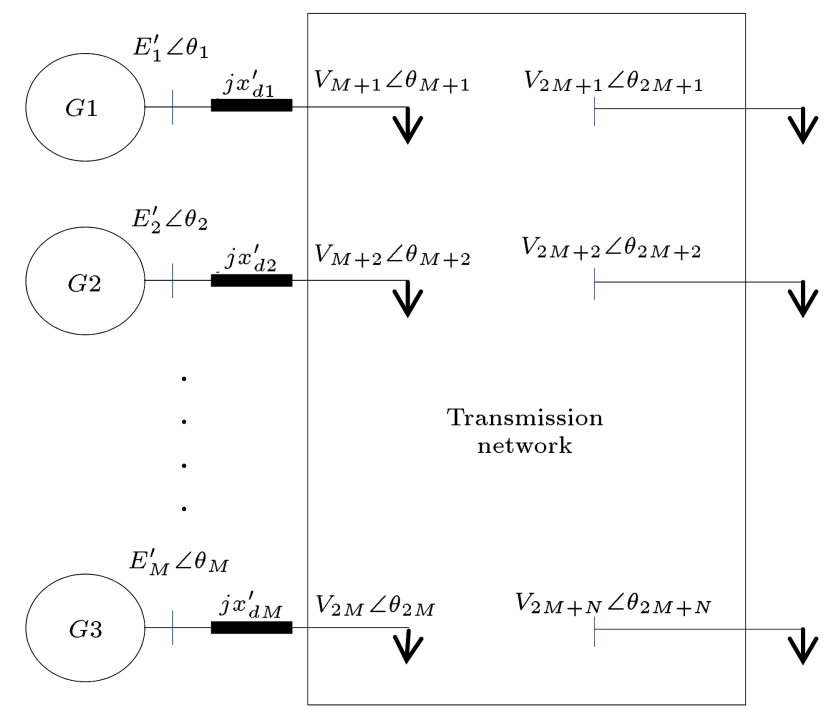

Figure 1. The typical layout of a multi-machine power system. 


$$
\begin{aligned}
P_{G i}= & \frac{1}{X_{d i}^{\prime}} E_{q i}^{\prime} V_{N+i} \sin \left(\delta_{i}-\theta_{N+i}\right) \\
& -\frac{x_{d i}^{\prime}-x_{q i}}{2 x_{d i}^{\prime} x_{q i}} V_{N+i}^{2} \sin \left(2\left(\delta_{i}-\theta_{N+i}\right)\right), \\
Q_{G i}= & \frac{1}{X_{d i}^{\prime}}\left[E_{q i}^{\prime} V_{N+i} \cos \left(\theta_{N+i}-\delta_{i}\right)-V_{N+i}^{2}\right] \\
& +\frac{x_{d i}^{\prime}-x_{q i}}{2 x_{d i}^{\prime} x_{q i}} V_{N+i}^{2}\left[\cos \left(2\left(\delta_{i}-\theta_{N+i}\right)-1\right)\right] .
\end{aligned}
$$

Active and reactive injection powers to buses are also defined as:

$$
\begin{aligned}
& n P_{k}=\sum_{i=n+1}^{n+N} B_{k i} V_{K} V_{i} \sin \left(\theta_{k}-\theta_{i}\right), \\
& Q_{k}=-\sum_{i=n+1}^{n+N} B_{k i} V_{k} V_{i} \cos \left(\theta_{k}-\theta_{i}\right) .
\end{aligned}
$$

The equilibrium of bus bar powers results in load flow equations specified as follows:

$$
\begin{aligned}
& P_{k}+P_{L k}-P_{G k}=0, \\
& Q_{k}+Q_{L k}-Q_{G k}=0 .
\end{aligned}
$$

\subsection{Principles and models of UPFC and OUPFC}

The OUPFC is composed of a full-scale PST and a small-sized UPFC linked by two triple winding transformers as shown in Figure 2. The PST injects a voltage with a fixed phase angle to the transmission line voltage, and its magnitude is controlled by mechanical or static switches. The power angle can be controlled by the injected voltage depending on system conditions. The small-sized UPFC, which is connected to a tertiary winding of the exciting and injecting transformers, is composed of two voltagesource converters in back-to-back configuration. The back-to-back converters operate through a common dclink, i.e. a dc capacitor [22] (Figure 3). Figure 4 shows the injection model of the UPFC located between buses $i$ and $j$ [27]. This model is used for the load flow and angle stability analysis. By assumption of $0 \leq r \leq 1$ as the radius of the UPFC operating region, $-\pi \leq \gamma \leq \pi$ as the UPFC phase angle, and $x_{s}$ as the transmission line reactance, the power injection model of UPFC is as follows:

$$
\begin{aligned}
& P_{s i}=b_{s} V_{i} V_{j}\left(u_{u p 1} \sin (\delta)+u_{u p 2} \cos (\delta)\right), \\
& P_{s j}=-P_{s i}, \\
& Q_{s i}=u_{u p 1} b_{s} V_{i}^{2}, \\
& Q_{s j}=-b_{s} V_{i} V_{j}\left(u_{u p 1} \cos (\delta)-u_{u p 2} \sin (\delta)\right),
\end{aligned}
$$

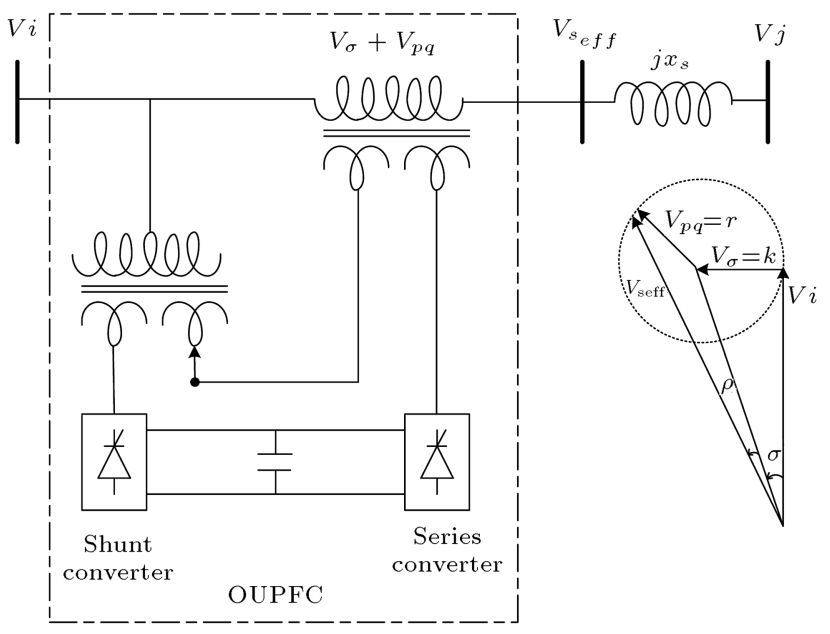

Figure 2. Basic scheme and phasor diagram of OUPFC.

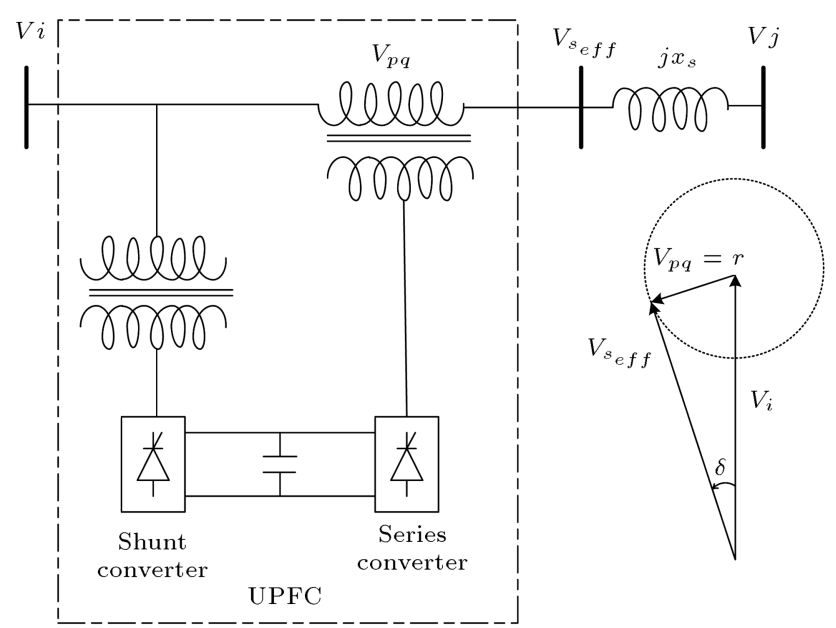

Figure 3. Basic scheme and phasor diagram of UPFC.

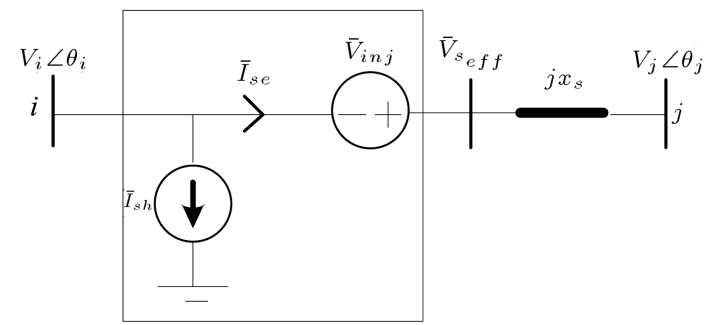

Figure 4. Equivalent circuit diagram of a CSD.

such that:

$$
\begin{aligned}
& b_{s}=\frac{1}{x_{s}}, \quad \delta=\theta_{i}-\theta_{j}, \\
& u_{u p 1}=r \cos (\gamma), \quad u_{u p 2}=r \sin (\gamma), \\
& r=\sqrt{u_{u p 1}^{2}+u_{u p 2}^{2}}, \quad \gamma=\arctan \left(\frac{u_{u p 2}}{u_{u p 1}}\right) .
\end{aligned}
$$

The schematic and phasor diagrams of OUPFC are shown in Figure 2. Similarly, the power injection model 
of OUPFC can be expressed by assuming that the radius of the OUPFC operating region is $0 \leq r \leq 0.15$, the UPFC phase angle of OUPFC is $-\pi \leq \rho \leq \pi$, and the PST phase angle of OUPFC is $-20^{\circ} \leq \sigma \leq$ $20^{\circ}[21,27]$ :

$$
\begin{aligned}
P_{i, \text { OUPFC }}= & -b_{s} k V_{i} V_{j} \sin (\delta+\sigma)-b_{s} r V_{i} V_{j} \sin (\delta+\rho), \\
Q_{i, \text { OUPFC }}= & -b_{s} V_{i}^{2}\left(k^{2}+r^{2}\right)-2 b_{s} k r V_{i}^{2} \cos (\sigma-\rho) \\
& -2 b_{s} k V_{i}^{2} \cos (\sigma)-2 b_{s} r V_{i}^{2} \cos (\rho) \\
& +b_{s} k V_{i} V j \cos (\delta+\sigma) \\
& +b_{s} r V_{i} V_{j} \cos (\delta+\rho), \\
P_{j, \text { OUPFC }}= & -P_{i, \text { OUPFC }}, \\
Q_{j, \text { OUPFC }}= & +b_{s} k V_{i} V_{j} \cos (\delta+\sigma)+b_{s} r V_{i} V_{j} \cos (\delta+\rho),
\end{aligned}
$$

where $k$ is the transfer ratio of $\operatorname{PST}(k=\tan \sigma)$.

\section{Direct methods and control Lyapunov functions}

In this section, the basic concepts of direct methods are briefly presented, and then a control Lyapunov function is developed.

\subsection{Direct methods}

The direct method of Lyapunov (energy function) for modeling of the power system can be defined as [25]:

$$
v\left(\tilde{\omega}, \tilde{\delta}, E_{q}^{\prime}, V, \tilde{\theta}\right)=v_{1}+\sum_{k=1}^{8} v_{2 k}+C_{0},
$$

where $v_{1}$ and $V_{2} k$ are kinetic and potential energies, respectively. $C_{0}$ is a constant, and it is defined, such that the whole energy of the system is zero, when it is stable. $v_{2 k}$ is defined as:

$$
\begin{aligned}
v_{21}= & -\sum_{k=1}^{n} P_{m k} \tilde{\delta}_{k}, \\
v_{22}= & \sum_{k=M+1}^{n+N} P_{L k} \theta_{k}, \\
v_{23}= & \sum_{k=n+1}^{n+N} \int \frac{Q_{L k}}{V_{k}} d V_{k}, \\
v_{24}= & \sum_{k=n+1}^{2 n} \frac{1}{2 x_{d k-M}^{\prime}}\left[E_{q k-n}^{\prime}{ }^{2}+V_{k}^{2}\right. \\
& \left.-2 E_{q k-n}^{\prime} V_{k} \cos \left(\delta_{k-n}-\theta_{k}\right)\right],
\end{aligned}
$$

$$
\begin{aligned}
v_{25}= & -\frac{1}{2} \sum_{k=n+1}^{n+N} \sum_{l=n+1}^{n+N} B_{k l} V_{k} V_{l} \cos \left(\theta_{k}-\theta_{l}\right) \\
v_{26}= & \sum_{k-n+1}^{2 n} \frac{x_{d k-n}^{\prime}-x_{q k-n}}{4 x_{d k-n}^{\prime} x_{q k-n}}\left[V_{k}^{2}\right. \\
& \left.-V_{k}^{2} \cos \left(2\left(\delta_{k-n}-\theta_{k}\right)\right)\right] \\
v_{27}= & -\sum_{k-1}^{n} \frac{E_{f d k} E_{q k}^{\prime}}{x_{d k}-x_{d k}^{\prime}}, \\
v_{28}= & \sum_{k=1}^{n} \frac{E_{q k}^{\prime 2}}{2\left(x_{d k}-x_{d k}^{\prime}\right)} .
\end{aligned}
$$

And finally, time derivative of Lyapunov function is:

$$
\begin{aligned}
\dot{v}=\frac{d v}{d t}= & -\sum_{k=1}^{n} D_{k}\left(\tilde{\omega}_{k}\right)^{2} \\
& -\sum_{k=1}^{n} \frac{T_{d o k}^{\prime}}{x_{d k}-x_{d k}^{\prime}}\left(\dot{E}_{q k}^{\prime}\right)^{2} \leq 0 .
\end{aligned}
$$

In the steady state, the total energy, $V$, is zero, thus more negative value of $\dot{V}$ means that the system returns to the steady state faster, i.e. more damping for the first-swing oscillation occurs. One of the objectives of this paper is to mitigate the first-swing oscillation through providing more negative values for $\dot{V}$. According to [27], the control laws based on the Control Lyapunov Function (CLF) rely only on locally measurable quantities and are independent of system topology and modeling of power system components. Also, these control laws do not require information about the post-fault stable equilibrium point. Just as the existence of a Lyapunov function is necessary and sufficient for the stability of a system with no input, the existence of a CLF is also necessary and sufficient for the stability of a system with a control input.

\subsection{Control Lyapunov functions}

The control Lyapunov function for UPFC is developed in [27]. Based on Eqs. (8), (11), and (28) [28], the energy function of UPFC is derived as follows:

$$
\begin{aligned}
\dot{v}_{\mathrm{CSD}}= & -b_{s} V_{i}\left[u_{u p 1} \frac{d}{d t}\left(V_{i}-V_{j} \cos \theta\right)\right. \\
& \left.+u_{u p 2} \frac{d}{d t}\left(V_{j} \sin \theta\right)\right] .
\end{aligned}
$$

Based on Eqs. (15)-(18) [21] and (28) [28], the energy function for OUPFC can be developed as follows: 


$$
\begin{aligned}
\dot{v}_{\mathrm{CSD}}= & -b_{s} k \sin \sigma\left[\frac{d}{d t}\left(V_{i} V_{j} \sin \delta\right)\right. \\
& \left.-\frac{\cos \sigma}{\sin \sigma} \frac{d}{d t}\left(V_{i} V_{j} \cos \delta\right)\right]-b_{s}[k \cos \sigma \\
& \left.+\frac{1}{2} k^{2}\right] \frac{d}{d t}\left(V_{i}^{2}\right)-b_{s} u_{d}\left[-\frac{d}{d t}\left(V_{i} V_{j} \cos \delta\right)\right. \\
& \left.+\frac{1}{2}\left(u_{d}+2 k \cos \sigma+2\right) \frac{d}{d t}\left(V_{i}^{2}\right)\right] \\
& -b_{s} u_{q}\left[\frac{d}{d t}\left(V_{i} V_{j} \sin \delta\right)-\frac{1}{2}\left(u_{q}\right.\right. \\
& \left.+k \sin \sigma) \frac{d}{d t}\left(V_{i}^{2}\right)\right]
\end{aligned}
$$

where:

$$
\begin{aligned}
& u_{d}=r \cos (\rho), u_{q}=r \sin (\rho), \\
& u_{d}^{2}+u_{q}^{2}=r^{2} .
\end{aligned}
$$

The energy function (Eq. (29)) becomes a CLF for the control system, when $\dot{V}$ becomes negative. Control laws of UPFC were suggested as [28]:

$$
\left\{\begin{array}{l}
u_{u p 1}=k_{1} \frac{d}{d t}\left(V_{i}-V_{j} \cos (\theta)\right) \\
u_{u p 2}=k_{2} \frac{d}{d t}\left(V_{j} \sin (\theta)\right)
\end{array}\right.
$$

where $k_{1}$ and $k_{2}$ are positive gains, which are chosen to minimize energy equation.

Control laws for OUPFC with assumption of $\delta=$ $\theta-\theta,-20 \leq \sigma \leq 20$, and $b_{s}>0$ (if $b_{s}=0$, then $\dot{v}=0$ ) are suggested to satisfy Eq. (28) in the following conditions:

a) $\frac{d}{d t}\left(V_{i} V_{j} \sin \delta\right) \geq \frac{\cos \sigma}{\sin \sigma} \frac{d}{d t}\left(V_{i} V_{j} \cos \delta\right) \quad \sigma>0$.

(1) $\frac{d}{d t}\left(V_{i}^{2}\right) \geq 0, u_{d}$ and $u_{q}$ are equal to:

$$
\left\{\begin{array}{l}
u_{d}=-K_{1} \frac{d}{d t}\left(V_{i} V_{j} \cos d\right)+K_{2} \frac{d}{d t}\left(V_{i}^{2}\right) \\
u_{q}=K_{3} \frac{d}{d t}\left(V_{i} V_{j} \sin d\right)-K_{4} \frac{d}{d t}\left(V_{i}^{2}\right)
\end{array}\right.
$$

(2) $\frac{d}{d t}\left(V_{i}^{2}\right) \leq 0, u_{d}$ and $u_{q}$ are equal to Eq. (34), and:

$$
\cos \sigma \geq-\frac{1}{2} k
$$

b) $\frac{d}{d t}\left(V_{i} V_{j} \sin \delta\right) \leq \frac{\cos \sigma}{\sin \sigma} \frac{d}{d t}\left(V_{i} V_{j} \cos \delta\right) \quad \sigma<0$,

(1) $\frac{d}{d t}\left(V_{i}\right) \geq 0, u_{d}$ and $u_{q}$ are equal to Eq. (34).

(2) $\frac{d}{d t}\left(V_{i}^{2}\right) \leq 0, u_{d}$ and $u_{q}$ are equal to Eq. (34), and:

$$
\cos \sigma \leq-\frac{1}{2} k
$$

where $K_{1}$ to $K_{4}$ are positive coefficients which are selected in such a way to have the appropriate damping. In other cases, the overall sum of Eq. (30) must satisfy Eq. (28). Now, the derived CLFs should be evaluated.

\section{Study system}

To evaluate the developed CLFs for the OUPFC, a study system of a 5 -bus $500 \mathrm{kV} / 230 \mathrm{kV}$ system, including two synchronous machines, is considered, as shown in Figure 5. The system, connected in a loop configuration, consists essentially of five buses (B1 to B5) interconnected through three transmission lines (L1, L2, and L3) and two $500 \mathrm{kV} / 230 \mathrm{kV}$ transformers $\operatorname{Tr} 1$ and Tr2. Two power plants, located at the $230 \mathrm{kV}$ system, generate a total of $1500 \mathrm{MW}$. The equivalent of the external system is modeled by an infinite bus at bus $5(500 \mathrm{kV})$ with the capacity of 15000 MVA. A $200 \mathrm{MW}$ load is connected at bus B3. The details of the network parameters are given in Tables 1, 2, and 3 [29]. The UPFC and OUPFC are alternatively located between buses 2 and 3 by assuming $K_{1}=0.7, K_{2}=0.5$, and $\sigma=\pi / 7$. A symmetric three-phase short-circuit

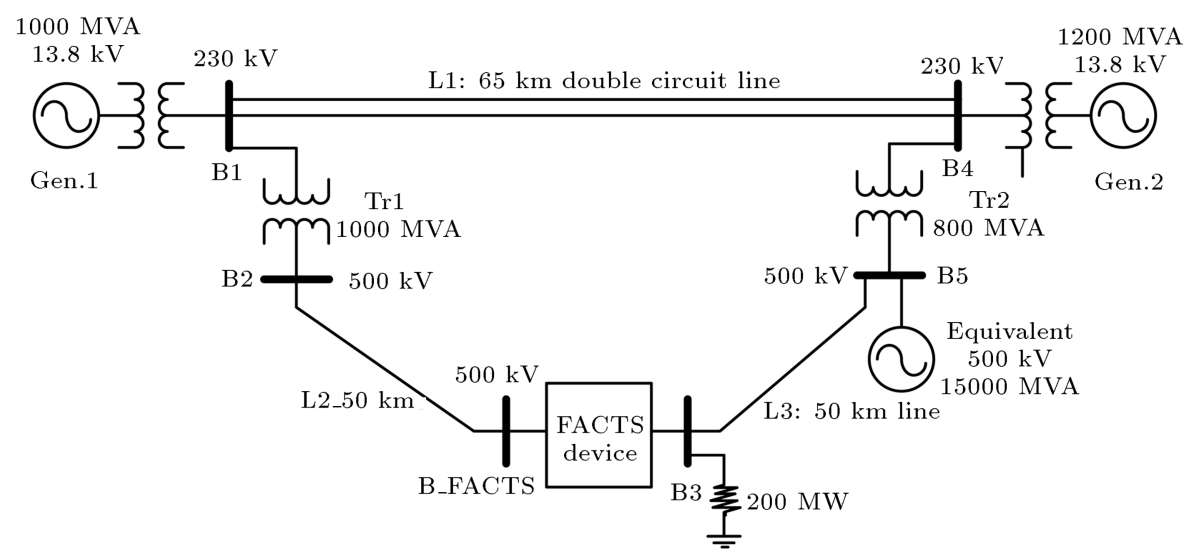

Figure 5. Single line diagram of the test system. 
Table 1. Transmission line data.

\begin{tabular}{|c|c|c|c|c|c|c|c|c|}
\hline $\begin{array}{l}\text { Bus } \\
\text { no. }\end{array}$ & $\begin{array}{l}\text { Bus } \\
\text { no. }\end{array}$ & $\begin{array}{c}\text { Ro } \\
(\mathrm{p.u.})\end{array}$ & $\begin{array}{c}\text { C0 } \\
(\text { p.u. })^{* 10-9}\end{array}$ & $\begin{array}{c}\text { L0 } \\
(\text { p.u. })^{* 10-3}\end{array}$ & $\begin{array}{c}\mathbf{R 1} \\
\text { (p.u.) }\end{array}$ & $\begin{array}{c}\mathrm{C1} \\
(\text { p.u. })^{* 10-9}\end{array}$ & $\begin{array}{c}\text { L1 } \\
(\text { p.u. })^{* 10-3}\end{array}$ & $\begin{array}{c}\text { line } \\
\text { length }(\mathrm{km})\end{array}$ \\
\hline 1 & 4 & 0.284 & 6.21 & 4.02 & 0.068 & 8.85 & 1.31 & 65 \\
\hline 2 & 3 & 0.3864 & 7.751 & 4.1264 & 0.02564 & 12.74 & 0.9337 & 50 \\
\hline 3 & 5 & 0.3864 & 7.751 & 4.1264 & 0.02564 & 12.74 & 0.9337 & 50 \\
\hline
\end{tabular}

Table 2. Data of resistance and reactance.

\begin{tabular}{cccccccc}
\hline Generator & Xd (p.u.) & $\mathbf{X}^{\prime} \mathbf{d}$ (p.u.) & $\mathbf{X}^{\prime \prime} \mathbf{d}$ (p.u.) & $\mathbf{X q}$ (p.u.) & $\mathbf{X}^{\prime} \mathbf{q}$ (p.u.) & $\mathbf{X}^{\prime \prime} \mathbf{q}$ (p.u.) & $\mathbf{R S}$ (p.u.)*10-3 \\
\hline 1 & 1.305 & 0.296 & 0.252 & 0.474 & 0.243 & 0.18 & 2.8544 \\
2 & 1.305 & 0.296 & 0.252 & 0.474 & 0.243 & 0.18 & 2.8544 \\
\hline
\end{tabular}

Table 3. Data of generators.

\begin{tabular}{ccccccccc}
\hline Generator & $\begin{array}{c}\text { Rated power } \\
(\mathbf{M V A})\end{array}$ & $\begin{array}{c}\text { Voltage } \\
(\mathbf{k V})\end{array}$ & $\begin{array}{c}\text { Frequency } \\
(\mathbf{H z})\end{array}$ & $\boldsymbol{H}$ (sec) & $\boldsymbol{P}$ & $\begin{array}{c}\boldsymbol{T}_{\boldsymbol{d}}^{\prime} \\
(\mathbf{s e c})\end{array}$ & $\begin{array}{c}\boldsymbol{T}_{\boldsymbol{d}}^{\prime \prime} \\
(\mathbf{s e c})\end{array}$ & $\begin{array}{c}\boldsymbol{T}_{\mathbf{q}}^{\prime \prime} \\
(\mathbf{s e c})\end{array}$ \\
\hline 1 & 1000 & 13.8 & 60 & 3.7 & 32 & 1.01 & 0.053 & 0.1 \\
2 & 1200 & 13.8 & 60 & 3.7 & 32 & 1.01 & 0.053 & 0.1 \\
\hline
\end{tabular}

fault to the ground occurs at bus 1 at $t=0.1 \mathrm{sec}$, and it is cleared at $t=0.2 \mathrm{sec}$. The impact of other control devices, such as PSS, is not considered in this study.

\subsection{Simulation results and discussions}

This section presents the simulation results and discussions. To investigate the impact of OPFC parameters on the dynamic behavior of the study system, i.e. the rotor angle, rotor speed, and active power G1 (on power plant 1) versus time, the following scenarios are considered:

1. No Compensation Devices (CDs) are in service;

2. Only a full-scale UPFC is in service;

3. Only an OUPFC is in service.

The simulation results for these scenarios are shown in Figures 6 to 8 . Figure 6 shows the rotor phase angle of G2 with respect to G1. Figure 7 shows the rotor speed difference of G1 and G2. In addition, Figure 8 shows the active power of G1. These results show that if there are no $\mathrm{CDs}$ in service, the system experiences the first-swing instability due to the lack of sufficient deceleration energy in the system. Furthermore, it can be observed that implementation of OUPFC provides faster mitigation of the electromechanical oscillation compared with UPFC (Figures 6 and 7 ), in which $\omega=d \delta / d t$. Figure 6 shows that the rotor angle of UPFC is displaced after $t=5 \mathrm{sec}$, but rotor angle experiences smooth variation as a result of OUPFC controller. Also, smaller amplitude variation of rotor speed and active power in Figures 7 and 8 confirms how OUPFC enlarges stability region and

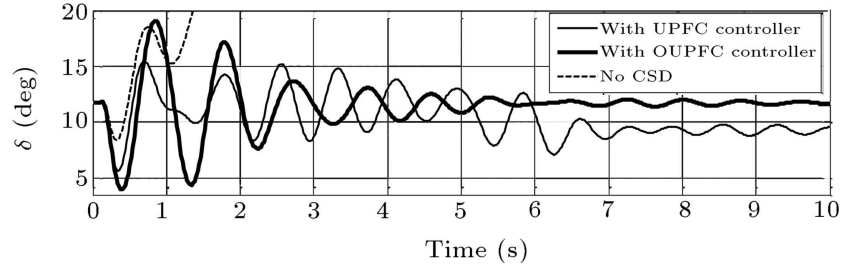

Figure 6. Variation of rotor angle difference between Generators 1 and 2.

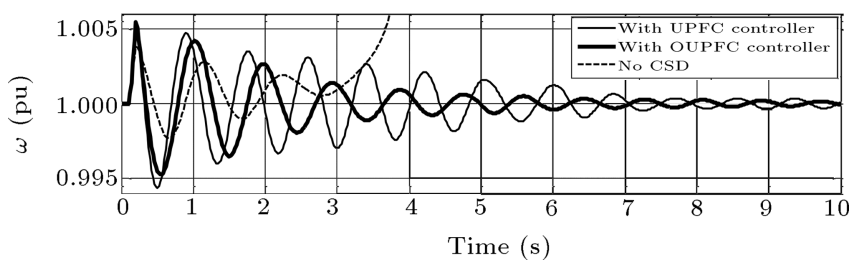

Figure 7. Variation of rotor speed difference between Generators 1 and 2.

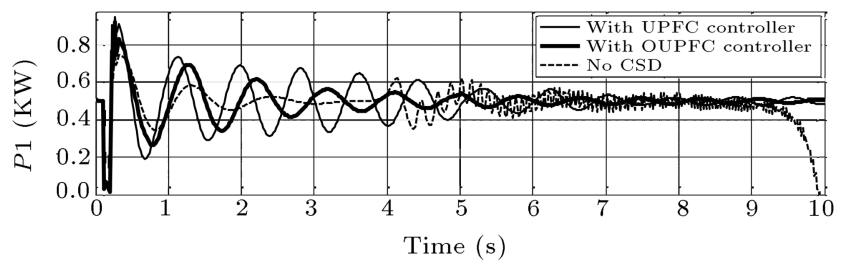

Figure 8. Variation of active power G1 vs. time.

provides more stable power region. This enhancement can also be observed in the phase portrait of UPFC and OUPFC, as shown in Figure 9. The phase portrait convergence with OUPFC is roughly the same as that of UPFC when it is in service. The fluctuation of UPFC and OUPFC energy functions incorporating 


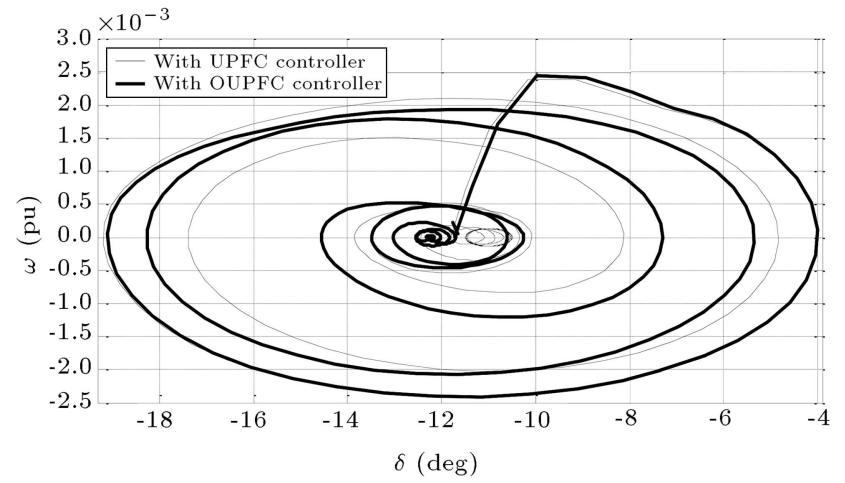

Figure 9. Phase portrait during the fault.

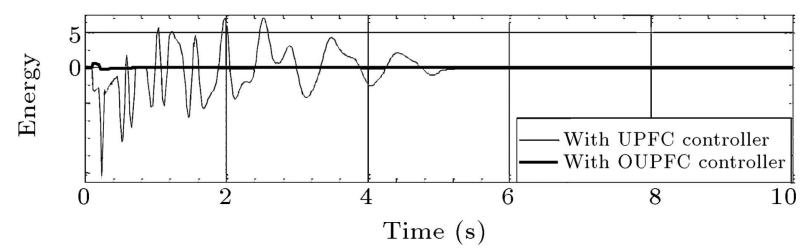

Figure 10. Variation of energy function vs. time.

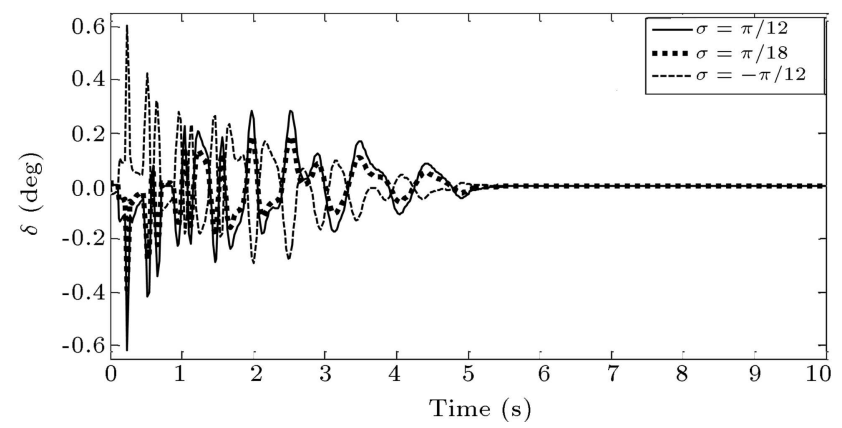

Figure 11. Variation of rotor angle G1 vs. time in terms of various $\sigma$.

their signs is presented in Figure 10. The OUPFC energy function is damped very fast with considerable less swing compared to that of UPFC, and there is an emphasis on the more negative $\dot{V}$ of OUPFC.

The most significant characteristics of OUPFC are its ability to change the phase angle of the output voltage, i.e. $\sigma$. Figure 11 shows that the swing curves of rotor angles are completely changed due to the variation of $\sigma$. Despite the rotor angle' changes due to different values of $\sigma$, active power is not altered (see Figure 12). It is because of the less priority role that $\sigma$ plays for controlling the real power compared to control parameters $u_{d}$ and $u_{q}$. Also, Figure 11 illustrates the capability of phase displacement compensation of OUPFC by shifting the operating point (during fault) due to $\sigma$ variations.

\section{Conclusion}

In this paper, an energy function (Lyapunov) controller is used for a hybrid FACTS device, i.e. OUPFC, to

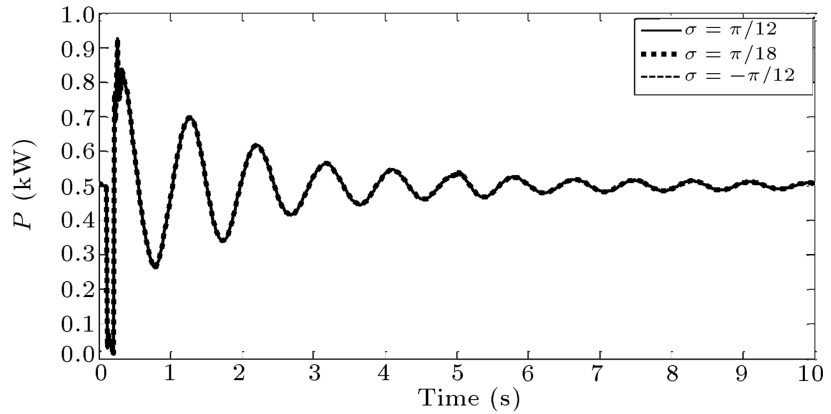

Figure 12. Variation of active power G1 vs. time in terms of various $\sigma$.

improve the transient stability. The time derivative of OUPFC Lyapunov function is a larger negative value compared to that of UPFC. Therefore, the OUPFC can provide more stable region than UPFC to control electromechanical oscillations as well as to enjoy the benefits of the UPFC. In addition to the increase in electromechanical oscillation damping, the most notable characteristics of employing OUPFC are that the operating requirements for unequal operating range and steady-state angular shift are satisfied to provide fixed or selectable transmission angle of advancement or retardation in the operating regions compared to that of UPFC. Thus, OUPFC can provide a constant or selectable angle of lead/lag phase compensation. Furthermore, it is expected that the proposed controller of OUPFC be favorable and play a more active role in the power system stability. The direct methods are powerful and fast stability assessment tools, such as the transient stability, to acquire critical clearing time assessment of the power system; however, there are still some difficulties in applying direct methods to large power systems which can be noted as a good subject for future studies.

\section{Nomenclature}

$\delta_{i} \quad$ Rotor angle of $i$ th machine

$\omega_{i} \quad$ Rotor speed of $i$ th machine

$M_{i} \quad$ Inertia constant of $i$ th machine

$P_{G i} \quad$ Electrical power of $i$ th machine

$D_{i} \quad$ Damping constant of $i$ th machine

$P_{m i} \quad$ Mechanical power of $i$ th machine

$x_{d i} \quad$ D-axis synchronous reactance of the $i$ th machine

$x_{q i} \quad$ Q-axis synchronous reactance of the $i$ th machine

$T_{d o i^{\prime}} \quad$ D-axis transient open-circuit time constant of $i$ th machine

$E_{f d i} \quad$ Exciter voltage of $i$ th machine

$E_{q i}^{\prime} \quad$ Q-axis voltage behind transient reactance of $i$ th machine

$x_{i}^{\prime} \quad$ Transient reactance of $i$ th machine 
$\bar{v}_{i}$

Load bus voltage phasor with magnitude $V_{i}$ and phase angle

$E_{f d i}$ Excitation voltage of $i$ th generator

\section{References}

1. Kundur, P., Paserba, J., Ajjarapu, V., et al. "Definition and classification of power system stability IEEE/CIGRE joint task force on stability terms and definitions", IEEE Transactions on Power Systems, 19, pp. 1387-1401 (2004).

2. Annakkage, U., Nair N.-K, C., Liang, Y., et al. "Dynamic system equivalents: A survey of available techniques", IEEE Transactions on Power Delivery, 27, pp. 411-420 (2012).

3. Kumar, A. and Priya, G. "Power system stability enhancement using FACTS controllers", Int. Conf. on Emerging Trends in Electrical Engineering and Energy Management (ICETEEEM), Chennai, India, pp. 84-87 (2012).

4. Noroozian, M. and Andersson, G. "Power flow control by use of controllable series components", IEEE Transactions on Power Delivery, 8, pp. 1420-1429 (1993).

5. Zhensheng, W., Ronghuan, G. and Lu, Y., The Simulation of Static and Transient Stability Enhancement of Power System by Installing UPFC, Springer Transactions, 377, pp. 523-532 (2016).

6. Mihalic, R., Zunko, P. and Povh, D. "Improvement of transient stability using unified power flow controller", IEEE Transactions on Power Delivery, 11, pp. 485-492 (1996).

7. Gyugyi, L., Schauder, C., Williams, S., Rietman, T., Torgerson, D. and Edris, A. "The unified power flow controller: a new approach to power transmission control", IEEE Transactions on Power Delivery, 10, pp. 1085-1097 (1995).

8. Raju, R.G.G. and Subramaniam, N. "Transient stability analysis employing equal area criterion", 1st Int. Conf. on Electrical Energy Systems (ICEES), New port Beach, Canada, pp. 275-280 (2011).

9. Ribbens-Pavella, M., Ernst, D. and Ruiz-Vega, D., Transient Stability of Power Systems: A Unified Approach to Assessment and Control, 581, Springer Press (2000).

10. Chiang, H.-D., Direct Methods for Stability Analysis of Electric Power Systems: Theoretical Foundation, BCU Methodologies, and Applications, Wiley Press (2011).

11. Gabrijel, U. and Mihalic, R. "Direct methods for transient stability assessment in power systems comprising controllable series devices", IEEE Transactions on Power Systems, 17(4), pp. 1116-1122 (2002).

12. Al Marhoon, H., Leevongwat, I. and Rastgoufard, P. "A practical method for power systems transient stability and security analysis", Transmission and Distribution Conference and Exposition (T\&D), Orlando, USA, pp. 1-6 (2012).
13. Sassano, M. and Astolfi, A. "Dynamic Lyapunov functions: properties and applications", American Control Conf. (ACC), Montreal, Canada, pp. 25712576 (2012).

14. Ghandhari, M. "Application of control Lyapunov functions to static var compensator", in Proceedings of the Int. Conf. on Control Applications, Glasgow, Scotland, U.K., pp. 1-6 (2002).

15. Sebastian, B. and GARG, R. "Transient stability analysis of multi-machine power system and first swing stability analysis using SVC", Int. Conf. on Advances in Electrical Engineering (ICAEE), Vellore, India, pp. 1,4, 9-11 (2014).

16. Shotorbani, A.M., Ajami, A., Aghababa, M.P. and Hosseini, S.H. "Direct Lyapunov theory-based method for power oscillation damping by robust finite-time control of unified power flow controller", IET Generation, Transmission \& Distribution, 7, pp. 691-699 (2013).

17. Sun, J., Zheng, H., Chai, Y., Hu, Y., Zhang, K. and Zhu, Z. "A direct method for power system corrective control to relieve current violation in transient with UPFCs by barrier functions", Elsevier Int. J. of Electrical Power \& Energy Systems, 78, pp. 626-636 (2016).

18. Siqueira, D.S., Alberto, L.F.C. and Bretas, N.G. "Generalized control energy function for controllable TCSC devices", IEEE on Power and Energy Society General Meeting (PES), Vancouver, Canada, pp. 1-5 (2013).

19. Colvara, L.D., Araujo, S.C.B. and Festraits, E.B. "Stability analysis of power system including FACTS (TCSC) effects by direct method approach", Int. J. of Electrical Power \& Energy Systems, 27, pp. 264-274 (2005).

20. Lyman, W. "Controlling power flow with phase shifting equipment", Transactions of the American Institute of Electrical Engineers, 49, pp. 825-829 (1930).

21. Lashkar Ara, A., Kazemi, A. and Nabavi Niaki, S.A. "Modelling of optimal unified power flow controller (OUPFC) for optimal steady-state performance of power systems", Energy Conversion and Management, 52, pp. 1325-1333 (2011).

22. Nabavi-Niaki, A. and Iravani, M.R. "Steady-state and dynamic models of unified power flow controller (UPFC) for power system studies", IEEE Transactions on Power Systems, 11, pp. 1937-1943 (1996).

23. Lashkar Ara, A., Kazemi, A. and Behshad M. "Improving power systems operation through multiobjective optimal location of optimal unified power flow controller", Turkish J. of Electrical Engineering \& Computer Sciences, 21, pp. 1893-1908 (2013).

24. Lashkar Ara, A., Aghaei, J., Alaleh, M. and Barati, H. "Contingency-based optimal placement of optimal unified power flow controller (OUPFC) in electrical 
energy transmission systems", Scientia Iranica, 20, pp. 778-785 (2013).

25. Lashkar Ara, A., Shabani, M. and Nabavi Niaki, S.A. "Multi-objective optimal location of optimal unified power flow controller (OUPFC) through a fuzzy interactive method", Scientia Iranica, 22(6), pp. 2432-2446 (2015).

26. Srinivasa Rao, V. and Srinivasa Rao, R. "A generalized approach for determination of optimal location of OUPFC", Int. Conf. on Electrical, Electronics, Signals Communication and Optimization (EESCO), Visakhapatnam, pp. 1-6 (2015).

27. Ghandhari, M., Andersson, G. and Hiskens, I. "Control Lyapunov functions for controllable series devices", IEEE Transactions on Power Systems, 16, pp. 689-694 (2001).

28. Ghandhari, M. "Control Lyapunov functions: A control strategy for damping of power oscillations in large power systems", Ph.D. Dissertation, Royal Institute of Technology, KTH Royal Institute of Technology, Stockholm, Sweden (2000).

29. The Math Works Inc., Using MATLAB-SIMULINK (1999).

\section{Biographies}

Pantea Avaz Pour was born in Abadan, Iran, in 1979. She received her BSc degree in Electrical Engineering from Shahid Chamran University, Ahvaz, Iran in 2003, and MSc degree in Electrical Engineering from the Islamic Azad University, Dezful Branch, Dezful, Iran, in 2013. Her current research interests include stability, and control of power systems, and FACTS controllers.

Afshin Lashkar Ara (M'11-SM'15) was born in Tehran, Iran, in 1973. He received his BSc, MS, and $\mathrm{PhD}$ degrees in Electrical Engineering, respectively, from the Islamic Azad University, Dezful Branch, Dezful, Iran in 1995, University of Mazandaran, Babol, Iran in 2001, Iran University of Science and Technology (IUST), Tehran, Iran in 2011. He is currently a Faculty Member in Islamic Azad University, Dezful Branch, Dezful, Iran, as well as a senior member of IEEE Power and Energy Society (IEEE-PES). His current research interests include analysis, operation, and control of power systems, and FACTS controllers.

Seyed Ali Nabavi Niaki (M'92-SM'04) received the BSc and MSc degrees in Electrical Engineering from Amirkabir University of Technology, Tehran, Iran, in 1987 and 1990, respectively, and the $\mathrm{PhD}$ degree in Electrical Engineering from the University of Toronto, Toronto, ON, Canada, in 1996. He joined University of Mazandaran, Babol, Iran, in 1996 as a Faculty Member. Currently, he is a Senior Research Associate in the University of Toronto, ON, Canada. His current research interests include analysis, operation, control of power systems, and FACTS controllers. 